\title{
CORRIGENDUM
}

\section{Recent advances in fibre lasers for nonlinear microscopy}

C. Xu \& F. W. Wise

Nature Photon. 7, 875-882 (2013); published online 20 October 2013; corrected after print 28 October 2013.

In the version of this Review Article originally published online and in print, no competing financial interests were declared. However, the authors wish to acknowledge relevant patents. The competing financial interests statement in the HTML and PDF versions of the Review Article has been modified to that shown below:

F. W. Wise is a named inventor on US patent US 8,416,817 B2 (publication date 04.09.2008, filing date 18.09.2007) and Chinese patent number 200780042670.8, which are related to the dissipative-soliton laser described in this Review Article. European patent application number 7873804.4 has been filed on the same subject. Wise has also submitted a patent application relating to picosecondpulse sources for coherent anti-Stokes Raman microscopy (international patent PCT/US/2012/058817 (publication date 11.04.2013, filing date 04.10.2011). 